\title{
Neuro-Ophthalmic Complications of Vestibular Schwannoma Resection: Current Perspectives
}

\author{
Stephanie J Chiu (D) ${ }^{1,2}$ \\ Simon J Hickman (D) ${ }^{2,3}$ \\ Irene M Pepper ${ }^{1,2}$ \\ Jennifer HY Tan ${ }^{1,2}$ \\ John Yianni ${ }^{2,4}$ \\ Joanna $M$ Jefferis (iD) 1,2,5 \\ 'Department of Ophthalmology, Royal \\ Hallamshire Hospital, Sheffield, UK; \\ ${ }^{2}$ Department of Medical Education, \\ University of Sheffield, Sheffield, UK; \\ ${ }^{3}$ Department of Neurology, Royal \\ Hallamshire Hospital, Sheffield, UK; \\ ${ }^{4}$ Department of Neurosurgery, Royal \\ Hallamshire Hospital, Sheffield, UK; \\ ${ }^{5}$ Department of Neuro-Ophthalmology, \\ Manchester Royal Eye Hospital, \\ Manchester, UK
}

\begin{abstract}
Vestibular schwannomas (VSs), also called acoustic neuromas, are benign intracranial neoplasms of the vestibulocochlear (VIII) cranial nerve. Management options include "wait-and-scan," stereotactic radiosurgery and surgical resection. Due to the proximity of the VIII nerve to the facial (VII) nerve in the cerebello-pontine angle, the VII nerve is particularly vulnerable to the effects of surgical resection. This can result in poor eye closure, lagophthalmos and resultant corneal exposure post VS resection. Additionally, compression from the tumor or resection can cause trigeminal (V) nerve damage and a desensate cornea. The combination of an exposed and desensate cornea puts the eye at risk of serious ocular complications including persistent epithelial defects, corneal ulceration, corneal vascularization, corneal melting and potential perforation. The abducens (VI) nerve can be affected by a large intracranial VS causing raised intracranial pressure (a false localizing sign) or as a result of damage to the VI nerve at the time of resection. Other types of neurogenic strabismus are rare and typically transient. Contralaterally beating nystagmus as a consequence of vestibular dysfunction is common post-operatively. This generally settles to pre-operative levels as central compensation occurs. Ipsilaterally beating nystagmus postoperatively should prompt investigation for post-operative cerebrovascular complications. Papilledema (and subsequent optic atrophy) can occur as a result of a large VS causing raised intracranial pressure. Where papilledema follows surgical resection of a VS, it can indicate that cerebral venous sinus thrombosis has occurred. Poor visual function following VS resection can result as a combination of all these potential complications and is more likely with larger tumors.
\end{abstract}

Keywords: vestibular schwannoma, post-operative complications, papilledema, facial nerve paralysis, neurotrophic keratopathy, nystagmus

\section{Introduction}

Vestibular schwannomas (VSs), also known as acoustic neuromas, are benign tumors of the vestibulocochlear (VIII) cranial nerve. The incidence of them is around 4 per 100,000 person-years and they make up approximately $8 \%$ of all primary adult intracranial neoplasms. ${ }^{1,2}$ VSs typically present with alterations in hearing and tinnitus due to compression of the VIII nerve at the internal acoustic meatus. However, smaller tumors often present incidentally on neuro-imaging ${ }^{2,3}$ and larger, more proximal tumors involving the cerebello-pontine angle may present with consequences of brainstem compression such as poor balance and vertigo. ${ }^{4}$ Less commonly, there may be consequences of raised intracranial pressure from a large tumor with features such as headache, vomiting and visual changes., Management strategies for VSs include "wait-and-scan," stereotactic radiosurgery
Correspondence: Joanna M Jefferis Manchester Royal Eye Hospital, Oxford Road, Manchester, MI3 9WL, UK Tel +44016I 276 I234

Email jojefferis@doctors.org.uk 
and surgical resection. The aim of treatment is to maximize tumor control whilst minimizing functional deficits. Surgical resection may occur via a translabyrinthine, retrosigmoid or middle cranial fossa approach. Choice of treatment is largely driven by tumor size and rate of growth, but also by patient factors as well as provider experience and expertise. ${ }^{1,6}$

The neuro-ophthalmic consequences following VS resection are neither infrequent nor innocuous and need to be considered carefully when making management choices. In one study of patient perceptions following neurosurgical management for VS, $90 \%$ of the 1651 respondents to a questionnaire reported eye problems following their VS surgery ${ }^{7}$ and eye problems were the third most common response to the question "What did you find was the one most difficult problem to deal with during the whole VS experience?" with hearing loss and facial weakness the two most common answers. ${ }^{7}$ Other questionnairebased surveys have shown that over $50 \%$ of respondents reported their vision had been affected following VS surgical resection, with $15 \%$ reporting their vision had been severely or very severely affected. ${ }^{8,9}$ In a survey which compared responses of 99 patients having surgical resection and 68 patients having stereotactic radiosurgery for their VS, $31 \%$ of patients in each group reported a drop in eyesight whilst $20 \%$ and $13 \%$ in the surgical and radiosurgery groups, respectively, reported "vision trouble."10

The VIII nerve emerges at the cerebello-pontine angle lateral to the facial nerve (VII) and they both exit from the cranium together via the internal auditory meatus. The trigeminal (V) nerve emerges from the pons superiorly and ventrally to the VII/VIII complex. The abducens nerve (VI) emerges at the ponto-medullary junction ventrally and medially to the VII/VIII complex and ascends superiorly on the ventral surface of the pons. The close approximation of these cranial nerves makes them potentially vulnerable to the effects of a VS or its resection. Figure 1 shows the MRI appearances of a VS pre- and post-surgical resection in the cerebello-pontine angle.

Our aims in this review are to discuss the neuroophthalmic consequences from VS resection, consider the causes for the high rates of reported eye problems and poor eyesight and to discuss how to manage and reduce neuro-ophthalmic morbidity due to VS treatment.

\section{Methods of Literature Search}

We conducted a search of published literature using MEDLINE. A broad search strategy with appropriate descriptors and keywords was used. Search terms included combinations of [eye diseases, vision disorders, facial nerve diseases, trigeminal nerve diseases, corneal diseases, post-operative complications] AND [acoustic neuroma, acoustic neuroma surgery, neurosurgical procedures]. In addition, our previous experience and knowledge was used to find articles. We searched the reference lists of identified primary reports and review articles to find further articles of interest.

\section{Facial (VII) Nerve Weakness}

The proximity of the VII nerve to the VIII nerve renders the VII nerve vulnerable to damage during VS treatment. Clinically apparent VII nerve palsy is rarely a feature of compression from the VS tumor itself but is a common cause of morbidity following microsurgical resection. ${ }^{1,7,11-13}$ The principal factor determining VII nerve damage at the time of surgical resection is the size of the VS itself, with tumor vascularity, the tumour micro-environment and tumour consistency also playing a part. ${ }^{14-20}$ Patients with VSs associated with neurofibromatosis type-2 also seem to be at risk of adverse VII nerve outcomes following surgical resection. ${ }^{21}$ With smaller tumors $(<20 \mathrm{~mm})$, rates of VII nerve palsy following VS resection are less than $10 \%,{ }^{16,19}$ but for larger tumors $(>30 \mathrm{~mm})$ VII nerve function is affected in more than half of patients undergoing surgical resection. ${ }^{22,23}$ A large study, including over 4000 patients from approximately $20 \%$ of all the hospitals in the United States of America, found that VII nerve palsy occurred in $14 \%$ of patients who had undergone VS surgical resection between 2002 and $2010 .^{24}$

There have been significant efforts to determine which surgical factors reduce the risk of damage to the VII nerve, with techniques such as intra-operative VII nerve monitoring and leaving a remnant of tumor around the VII nerve becoming more commonplace. ${ }^{16,25}$ VII nerve monitoring and direct nerve stimulation can warn the surgeon when a resection limit has been met at which a maximal amount of tumor has been excised without invasion of the VII nerve; it can also predict the risk of post-operative nerve damage. $^{26,27}$ Leaving a tumor remnant does seem to be predictive of better VII outcomes ${ }^{25,28}$ and this, alongside VII nerve monitoring, may account for declining rates of VII nerve paresis following VS resection. However, the direct impact of VII nerve monitoring on post-operative VII function is yet to be elucidated. ${ }^{16,27}$ Stereotactic radiosurgery has lower rates of post-treatment VII nerve 


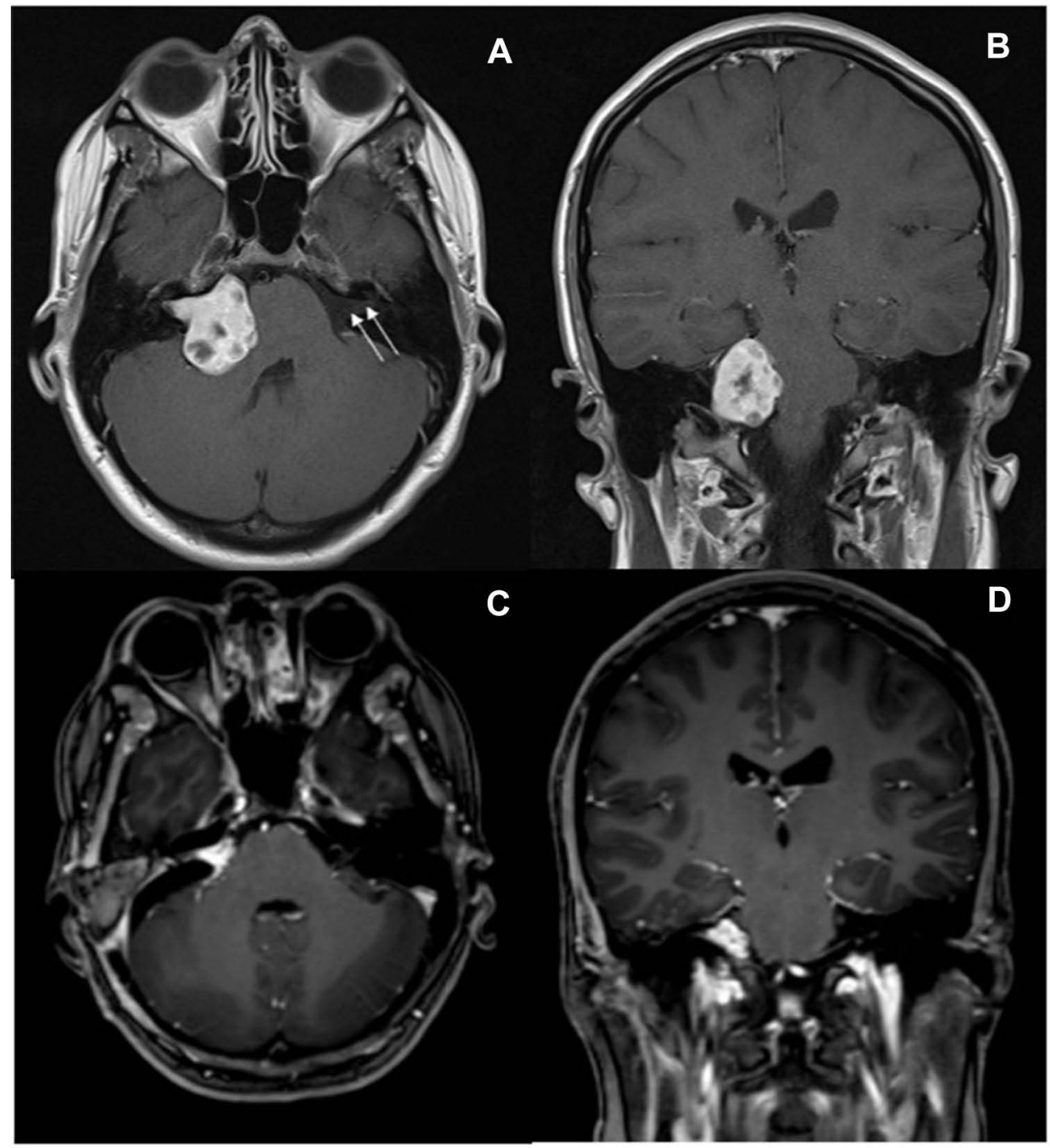

Figure I Contrast enhanced axial and coronal TI-weighted magnetic resonance images demonstrating a right sided vestibular schwannoma, pre-operatively (A and B) and post-operatively (C and D). Arrows demonstrate location of the VII/VIII nerve complex within the internal acoustic meatus of the contralateral, non-pathological side. The diameter of this tumour prior to resection was approximately $3 \mathrm{~cm}$ and note that it has caused distortion of the right side of the pons.

weakness with less than $1 \%$ of patients in our own neurosurgical unit having persistent VII nerve weakness following Gamma knife radiosurgery. ${ }^{29}$ Whilst traditionally reserved for smaller tumor sizes, stereotactic radiosurgery can achieve reasonable tumor control even for larger volume VSs of greater than $10 \mathrm{~cm}^{3} .^{30}$ It is not, however, suitable for tumors where there is evidence of significant brainstem compression (see Figure 1).

VII nerve damage results in impaired innervation of the orbicularis oculi muscle, which can result in lagophthalmos (incomplete eye closure); paralytic ectropion (outturned lower lid); impaired or absent blink; impaired Bell's phenomenon (the palpebral-oculogyric reflex which causes the eye to turn up and out on attempted blink); and upper lid retraction (due to the unopposed levator palpebrae superioris action, or as a reflex response to correct brow ptosis caused by VII nerve damage). ${ }^{31,32}$ All of these can contribute to exposure of the conjunctiva and cornea with resultant exposure keratopathy. VII nerve damage also results in reduced or absent lacrimation due to compromise of the nervus intermedius that innervates the lacrimal gland; this branch of the VII nerve carries the sensory and parasympathetic fibers, which lie between the VIII nerve and the motor branch of VII. ${ }^{31,33}$ This can leave the ocular surface deficient of its normal protective tear film. Both exposure keratopathy and a deficient tear film leave the cornea vulnerable, and can lead to a spectrum of corneal disease ranging from dry eye symptoms and superficial punctate keratitis at the mild end to recurrent corneal ulcers, corneal scarring, neovascularization, corneal 
abscesses and even corneal perforation at the severe end. In the presence of a desensate cornea, the risk of severe ocular complications is significantly greater. ${ }^{16,31,34,35}$

VII nerve function can be graded by the HouseBrackmann grading system, which ranges from I (normal) to VI (total VII nerve paralysis). ${ }^{36}$ While it does include eye closure assessment in each grading level, it is a grading system used to assess VII nerve function as a whole. It has been found to correlate poorly with corneal staining in VII nerve palsy (corneal staining is used as a surrogate marker to screen patients at risk of developing corneal complications). ${ }^{37}$ Hence, accurate assessment of ocular complications following VS resection relies on reporting of specific ocular complications, not just on the House-Brackmann grading. Sadiq and Downes $^{35}$ suggested that in terms of ocular considerations, grading a VII nerve palsy as mild (complete eye closure with minimal effort), moderate (complete eye closure with effort), or severe (incomplete eye closure) is more practically meaningful, and Meadows et al agreed. ${ }^{37}$

Over time, some recovery of VII nerve function can occur as the nerve regenerates but this can, in some cases, also lead to aberrant regeneration. In aberrant regeneration axons regenerate along the VII nerve to the incorrect target. $^{38}$ This "mis-wiring" can involve the motor and parasympathetic components of the VII nerve and can result in synkinesis (involuntary muscle movements accompanying voluntary movements) as well as unwanted lacrimation or salivation. ${ }^{39}$ Examples include lacrimation while eating (aberrant connections with the lacrimal ducts instead of the salivary gland); ptosis (due to increased orbicularis tone); lid closure and lacrimation with orofacial movements and oculo-oral synkinesis (involuntary eye closure during voluntary mouth movement). ${ }^{8,34,40,41}$ All of these can be extremely troubling for the patient.

Management of poor lid closure following VS resection will depend on the degree of lagophthalmos, the presence or otherwise of the Bell's phenomenon, and whether there is any sign of corneal exposure. The spectrum of treatments include copious lubrication; humidified air; moisture chambers; taping the lids; temporary procedures to change the position of the upper lid (eg toxin injection); permanent procedures to change the position of the upper lid (eg gold weight); procedures to tighten the lower lid; and temporarily or permanently closing the lids or part thereof with a tarsorrhaphy. ${ }^{42-44}$ Figure 2 shows an example of a patient with mild-moderate VII nerve weakness resulting in lagophthalmos who had symptoms and signs of corneal exposure despite a positive Bell's phenomenon. The usefulness of a temporary and permanent upper-lid weight in improving lagophthalmos is evident here.

\section{Trigeminal (V) Nerve Damage}

The V nerve sits slightly further away from the VIII nerve in the cerebello-pontine angle than the VII nerve, with the $\mathrm{V}$ nerve lying anteriorly and superiorly to the VII/VIII cranial nerve complex. It is, therefore, less at risk from the effects of VS resection when compared with the VII nerve. However, sensory nerves are more sensitive to compression from tumor mass effect than motor nerves. ${ }^{33,45}$ As a result of its sensitivity to the effects of compression, rates of $\mathrm{V}$ nerve palsy prior to $\mathrm{VS}$ resection are higher than that of VII nerve palsy prior to resection. Rates of corneal dysesthesia or facial dysesthesia are

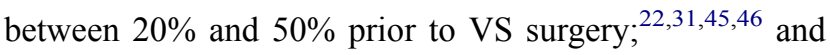
up to $70 \%$ in larger tumors (with an extrameatal diameter $>4 \mathrm{~cm}) .{ }^{47} \mathrm{~V}$ nerve outcomes following VS surgery are less commonly reported than VII nerve outcomes. When reported, the rates of corneal or facial hypoesthesia after VS resection vary widely between $2 \%$ and $40 \%{ }^{16,22,34,46,48}$ It is difficult to determine whether $\mathrm{V}$ nerve damage in these reports arose from the effects of the tumor or the effect of surgery. Whilst VII nerve function is clearly adversely affected by VS surgery, $\mathrm{V}$ nerve function may be more affected by the tumor itself over and above the surgery. With respect to Gamma knife radiosurgery, again the risks of treatment related $\mathrm{V}$ nerve injury are lower at around $1.5 \% .^{29}$ In either case, the presence of reduced or absent corneal sensation following VS treatment is ultimately associated with poorer visual outcomes. $^{34}$

$\mathrm{V}$ nerve palsy resulting in absent or reduced corneal sensation and an absent or reduced corneal reflex renders the cornea vulnerable and contributes to the development of neurotrophic keratitis. Corneal sensation and the corneal reflex serve as protective mechanisms preventing the cornea from being injured. Furthermore, a desensate cornea is likely to present later with disease due to the inability of the patient to feel an earlier insult. Lambiase et al demonstrated that $\mathrm{V}$ nerve damage following neurosurgery (for various pathologies including VS) induced long-term corneal functional and morphological changes, including a decrease in corneal endothelial cell density. ${ }^{49}$ This is because as well as providing sensation to the cornea, the $\mathrm{V}$ nerve plays a role in maintaining 

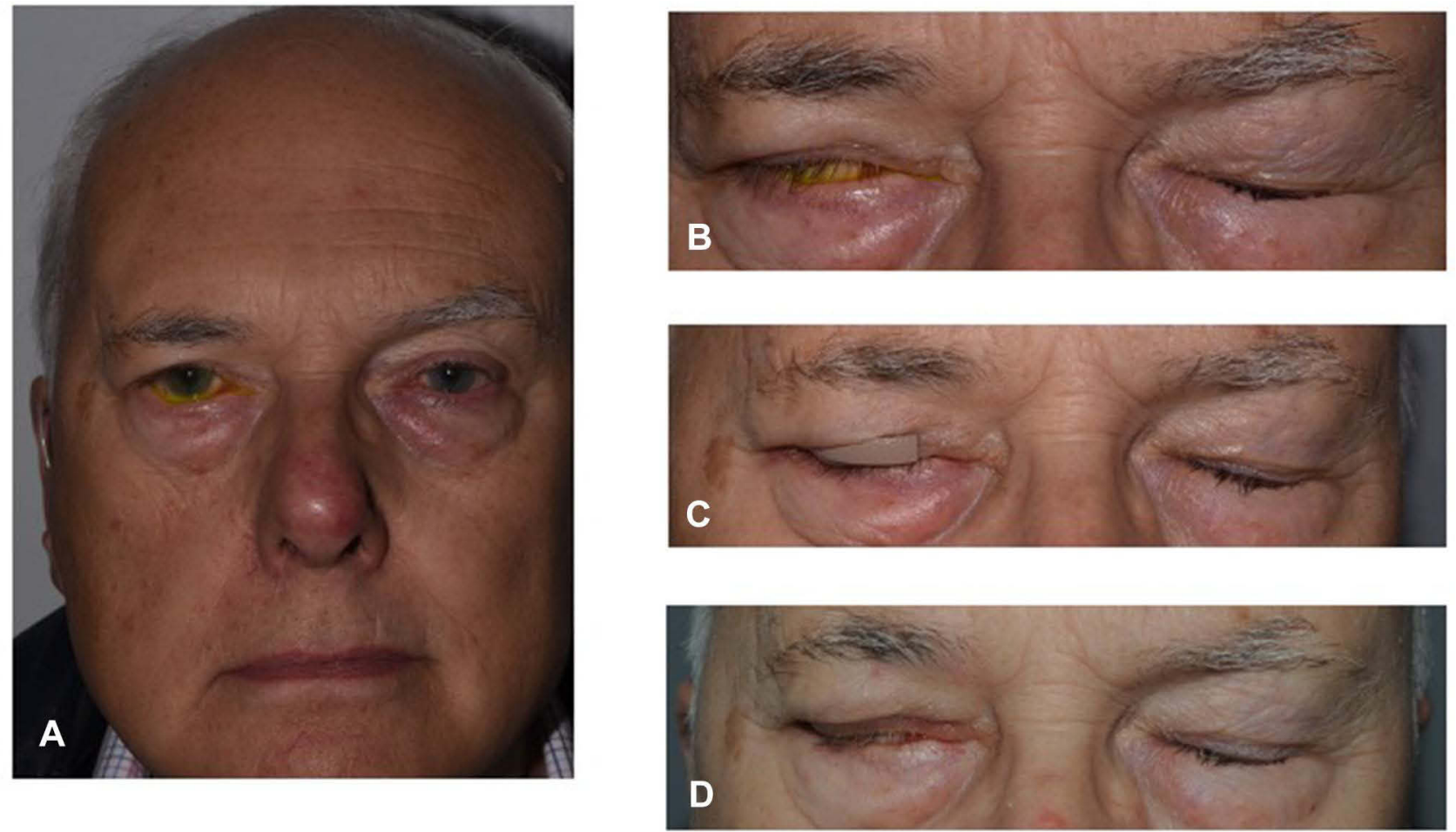

Figure 2 Moderate right VII nerve dysfunction (A) with lagophthalmos and a positive Bell's phenomenon (B). Temporary upper lid weight to the right upper lid (C) and post implantation of a permanent gold weight right upper lid (D). The patient has provided informed consent for this image to be published.

the integrity of the cornea by supplying it with trophic factors and regulating tissue metabolism. ${ }^{50}$ In combination with exposure of the eye and reduced lacrimation as a result of VII nerve palsy, the desensate cornea is particularly at risk. ${ }^{8,10,15,16,22,31,33-35,46}$

Patients with a desensate cornea need to be counseled about the risks of developing sight threatening corneal complications and the importance of presenting for urgent ophthalmic assessment should they develop a red eye or decreased vision. Regular lubrication with non-preserved preparations and careful monitoring is necessary with early involvement of corneal specialists for persistent epithelial defects. The spectrum of management strategies are aimed at promoting corneal healing and preventing progression of disease to corneal melting and perforation. It is vital to also treat exposure from poor lid closure as described above. The range of treatments for neurotrophic keratitis include topical antibiotics for secondary microbial keratitis; systemic doxycycline and vitamin $\mathrm{C}$ (which inhibit matrix metalloproteinases and pro-inflammatory cytokines and decrease toxic-free radicals); autologous serum drops; therapeutic contact lenses; amniotic membrane grafting and eyelid closure (tarsorrhaphy). ${ }^{50,51}$

\section{Facial (VII) and Trigeminal (V) Nerve Damage in Combination}

Several studies have shown that those patients particularly at high risk of developing ocular problems following VS surgery are those with evidence of both $\mathrm{V}$ nerve (corneal hypoesthesia) and VII nerve palsy, and that these patients should be referred for ophthalmological assessment earlier rather than later. ${ }^{8,10,15,16,22,31,33-35,46}$ The rates of these VII and V nerve-related ocular sequelae following VS surgery are summarized in Table 1 along with the reported management strategies. Figure 3 shows a flow diagram outlining the authors' management strategy for the ophthalmic management of VII and V nerve damage following VS resection.

\section{Double Vision and Strabismus}

Patient reported outcomes following VS surgery show that approximately 5\% will report double vision following VS resection and considerably more (30\%) may report being "slightly affected" by double vision. ${ }^{9,10}$ Care needs to be taken in interpreting these survey reports as a symptom of "double vision" requires the follow-on question "does the double vision resolve when one eye is covered?" to 
Table I The Rates of Facial (VII) and Trigeminal (V) Nerve Related Ocular Sequelae Following Vestibular Schwannoma (VS) Surgery as Well as the Frequency of Ophthalmic Procedures for Corneal Protection

\begin{tabular}{|c|c|c|c|c|}
\hline Study & Methods & Population & $\begin{array}{c}\text { Corneal and Adnexal } \\
\text { Complications }\end{array}$ & $\begin{array}{c}\text { Ophthalmic Procedures for } \\
\text { Corneal Protection }\end{array}$ \\
\hline $\begin{array}{l}\text { Goren (1975) } \\
\text { USA }^{48}\end{array}$ & Case note review & 29 patients following VS resection & SPKs/corneal erosions: $17 \%$ & $\begin{array}{l}\text { Scleral shell: } 6.9 \% \\
\text { Eyelid surgery: } 10 \%\end{array}$ \\
\hline $\begin{array}{l}\text { Jøgrensen and } \\
\text { Pedersen (1994) } \\
\text { Denmark }^{15}\end{array}$ & Case note review & $\begin{array}{l}59 \text { patients following VS resection } \\
\text { via translabyrinthine approach (in } \\
\text { 46) or suboccipital and/or } \\
\text { ventricular drainage (in 13) }\end{array}$ & Dry eyes: $40 \%$ & $\begin{array}{l}\text { Tarsorrhaphy: } 24 \% \\
\text { Rhytidectomy: } 12 \%\end{array}$ \\
\hline $\begin{array}{l}\text { Irving et al } \\
\text { (1995) UK }{ }^{33}\end{array}$ & $\begin{array}{l}\text { Patient } \\
\text { questionnaire }\end{array}$ & 224 patients following VS resection & $\begin{array}{l}\text { Crocodile tears: } 44 \% \\
\text { Absent/reduced lacrimation: } 72 \%\end{array}$ & None reported \\
\hline $\begin{array}{l}\text { Rogers and } \\
\text { Brand (1997) } \\
\text { UK }^{31}\end{array}$ & Case note review & $\begin{array}{l}\text { I38 patients following VS resection } \\
\text { via posterior fossa craniectomy ( } 97) \\
\text { or translabyrinthine approach }(4 \mathrm{I})\end{array}$ & $\begin{array}{l}\text { Superficial keratopathy: } 13 \% \\
\text { Corneal clouding } \pm \text { corneal } \\
\text { neovascularisation: } 9.4 \% \\
\text { Recurrent corneal abscess: } 1.5 \%\end{array}$ & $\begin{array}{l}\text { Lid surgery: } 44 \% \\
\text { Air to induce ptosis: } 9 \% \\
\text { Toxin to induce ptosis: } 1.5 \%\end{array}$ \\
\hline $\begin{array}{l}\text { Mulhern et al } \\
\text { (1999) Ireland }{ }^{34}\end{array}$ & $\begin{array}{l}\text { Ophthalmic } \\
\text { examination and } \\
\text { case note review }\end{array}$ & 62 patients following VS resection & $\begin{array}{l}\text { Lagophthalmos: } 32 \% \\
\text { Crocodile tears: } 7.0 \% \\
\text { Decreased/absent corneal } \\
\text { sensation: } 50 \% \\
\text { PEE: } 56 \% \\
\text { Corneal ulcer: } 9.6 \% \\
\text { Corneal scarring } \pm \\
\text { neovascularisation: } 15 \% \\
\text { Salzmann nodular degeneration: } \\
\text { I.6\% } \\
\text { Corneal perforation: } 4.8 \%\end{array}$ & $\begin{array}{l}\text { Penetrating keratoplasty: } 3.2 \% \\
\text { Evisceration: } 1.6 \% \\
\text { Tarsorrhaphy: } 32 \% \\
\text { Ectropion repair: } 3.2 \% \\
\text { Brow suspension: } 3.2 \% \\
\text { Toxin to induce ptosis: } 3.2 \% \\
\text { Gold weight implant: } 1.6 \% \\
\text { Lid spring implant: } 1.6 \%\end{array}$ \\
\hline $\begin{array}{l}\text { Tos et al (2003) } \\
\text { Denmark }^{8}\end{array}$ & $\begin{array}{l}\text { Patient } \\
\text { questionnaire }\end{array}$ & $\begin{array}{l}625 \text { patients following VS resection } \\
\text { (with over } 90 \% \text { via translabyrinthine } \\
\text { approach and the remainder } \\
\text { through a middle fossa or sub- } \\
\text { occipital approach) }\end{array}$ & $\begin{array}{l}\text { Dry eyes: } 58 \% \\
\text { Weeping when eating: } 38 \% \\
\text { Light sensitivity: } 20 \%\end{array}$ & $\begin{array}{l}\text { Tarsorrhaphy: } 22 \% \\
\text { Gold weight: } 0.6 \% \\
\text { Lid spring implant: } 0.5 \% \\
\text { Blepharoplasty: } 1.6 \% \\
\text { Other lid surgery: } 2.1 \%\end{array}$ \\
\hline \multirow[t]{2}{*}{$\begin{array}{l}\text { Tamura et al } \\
\text { (2004) France }\end{array}$} & \multirow[t]{2}{*}{$\begin{array}{l}\text { Patient } \\
\text { questionnaire and } \\
\text { Schirmer's test }\end{array}$} & $\begin{array}{l}68 \text { patients following radiosurgery } \\
\text { for VS }\end{array}$ & $\begin{array}{l}\text { Dry eye: } 13 \% \\
\text { Crocodile tears: } 1.5 \% \\
\text { Burning eye: } 15 \% \\
\text { Epiphora: } 15 \%\end{array}$ & None reported \\
\hline & & 99 patients following VS resection & $\begin{array}{l}\text { Dry eye: } 25 \% \\
\text { Crocodile tears: } 12 \% \\
\text { Burning eye: } 27 \% \\
\text { Epiphora: } 39 \%\end{array}$ & None reported \\
\hline $\begin{array}{l}\text { Coca Pelaz } \\
\text { (2008) Spain }\end{array}$ & Case note review & $\begin{array}{l}30 \text { patients (from a cohort of } 120 \text { ) } \\
\text { who had complete VII nerve } \\
\text { palsy day one post VS resection (I6 } \\
\text { retrosigmoid and I5 } \\
\text { translabyrinthine) }\end{array}$ & Corneal ulcer: $6.7 \%$ & $\begin{array}{l}\text { Gold weight: } 6.7 \% \\
\text { Tarsorrhaphy: } 6.7 \% \\
\text { Penetrating keratoplasty: } 6.7 \%\end{array}$ \\
\hline $\begin{array}{l}\text { McClelland } \\
(2011) \cup S A^{53}\end{array}$ & $\begin{array}{l}\text { Data from } \\
\text { hospital discharge } \\
\text { database }\end{array}$ & $\begin{array}{l}4886 \text { patients following VS } \\
\text { resection }\end{array}$ & $\begin{array}{l}\text { Lagophthalmos: } 1.5 \% \\
\text { Corneal ulcer, keratoconjunctivitis, } \\
\text { or other keratopathy: } 2.1 \%\end{array}$ & Blepharoplasty/tarsorrhaphy: $4.1 \%$ \\
\hline
\end{tabular}

(Continued) 
Table I (Continued).

\begin{tabular}{|l|l|l|l|l|}
\hline Study & \multicolumn{1}{|c|}{ Methods } & \multicolumn{1}{|c|}{ Population } & \multicolumn{1}{c|}{$\begin{array}{c}\text { Corneal and Adnexal } \\
\text { Complications }\end{array}$} & $\begin{array}{c}\text { Ophthalmic Procedures for } \\
\text { Corneal Protection }\end{array}$ \\
\hline $\begin{array}{l}\text { Karkas (2014) } \\
\text { France }\end{array}$ & Case note review & $\begin{array}{l}53 \text { patients following VS resection } \\
\text { (translabyrinthine in 44, } \\
\text { retrosigmoid, transcochlear or } \\
\text { retrolabyrinthine in the remainder) }\end{array}$ & $\begin{array}{l}\text { Absent corneal reflex: } 49 \% \\
\text { Keratitis: } 21 \%\end{array}$ & None reported \\
\hline $\begin{array}{l}\text { Al-Shudifat } \\
(2016) \text { Jordan9 }\end{array}$ & $\begin{array}{l}\text { Patient } \\
\text { questionnaire }\end{array}$ & $\begin{array}{l}\text { I67 patients following VS resection } \\
\text { (translabyrinthine in } 88 \text { and } \\
\text { retrosigmoid in 52) }\end{array}$ & Eye irritation: $>70 \%$ & None reported \\
\hline $\begin{array}{l}\text { Gange (2018) } \\
\text { USA }{ }^{16}\end{array}$ & Case note review & $\begin{array}{l}\text { I74 patients following VS resection } \\
\text { (retrosigmoid in 97; } \\
\text { translabyrinthine in 59; and } \\
\text { combined in 18) }\end{array}$ & $\begin{array}{l}\text { Lagophthalmos: } 21 \% \\
\text { Dry eye: } 16 \% \\
\text { Ptosis: } 5.2 \% \\
\text { Epiphora: } 5.2 \% \\
\text { Exposure keratopathy: } 4.6 \% \\
\text { Ectropion: } 0.6 \%\end{array}$ & $\begin{array}{l}\text { Taping and patching: } 18 \% \\
\text { Tarsorrhaphy: } 2.9 \% \\
\text { Gold weight: } 2.3 \%\end{array}$ \\
Punctal occlusion: $1.1 \%$
\end{tabular}

distinguish binocular diplopia from monocular diplopia. The latter could well be caused by the VII and V nerverelated ocular sequelae described in Table 1. Reasons for true binocular diplopia in the case of a VS include damage to the VI, or less commonly, III (oculomotor) IV (trochlear) cranial nerves and, less commonly again, skew deviations.

The position of the VI nerve (which innervates the lateral rectus muscle) on the anterior surface of the pons and running upwards means that it is generally spared from compression by a small or medium sized VS, which will sit laterally to the nerve. However, VI nerve palsy, indicated by an esotropia and/or diplopia on ipsilateral gaze, can be present in some patients as a presenting feature of a VS. In these cases, the VI nerve palsy may be due to direct compression, or as a result of raised intracranial pressure (as a "false localizing sign"). Rogers and Brand felt that for the 7\% patients in their series who had signs of a VI nerve palsy prior to VS resection, this was most likely the result of raised intracranial pressure, because of the correlation with papilledema, and the lack of correlation between pre- and post-operative VI nerve involvement. ${ }^{31}$ Following VS resection, VI nerve palsies are relatively rare, with Sylvester et al finding $<1 \%$ of over 4000 patients who had undergone VS resection in the USA to have a VI nerve palsy. ${ }^{24}$ In Rogers and Brand's series, whilst $7 \%$ patients had a VI nerve palsy prior to VS resection, only $4 \%$ patients had a VI nerve palsy following resection. ${ }^{31}$ In Roland et al's. series of large $(>3 \mathrm{~cm})$ VS resections in New York, 2/54 patients had a new VI nerve palsy following VS surgery as a result of intracranial hemorrhage, and one patient had their VI nerve transected intra-operatively. ${ }^{54}$ The rates of VI nerve palsy following VS resection may be higher following the excision of larger tumors, but for many these affects will be transitory. ${ }^{22}$ Where there is a VI nerve palsy in the presence of a VII and/or V nerve palsy, this will further put the cornea at risk of exposure by leaving the globe in an adducted position where it is most at risk of exposure.

The IV and III cranial nerves emerge from the midbrain superior to the cerebello-pontine angle and are generally spared either compression by a large VS or the effects of resection. However, there are reports of them being affected following VS resection. Rogers and Brand reported one $(0.7 \%)$ patient with a post-operative IVth nerve palsy, one $(0.7 \%)$ with a post-operative III nerve palsy and one $(0.7 \%)$ with an internuclear ophthalmoplegia. ${ }^{31}$ However, in the Sylvester series of over 4000 patients following VS resection, less than $0.25 \%$ had an IV nerve palsy and none were reported to have III palsy. ${ }^{24}$ The reasons for these are not entirely clear, since direct damage or transection of the nerves is unlikely. However, intra-operative or postoperative bleeding or edema could leave these cranial nerves subject to compromise, particularly the IV cranial nerve with its long and tenuous intracranial course.

Skew deviation is a vertical ocular misalignment caused by a central or peripheral lesion to the vestibular pathway. ${ }^{55}$ It is most commonly associated with a brainstem lesion damaging the supranuclear vestibular pathway to the IIIrd and IVth nerve nuclei. However, peripheral vestibular lesions can also cause skew deviations. Cosetti et al described a case series of three patients who underwent cerebello-pontine angle surgery (two 


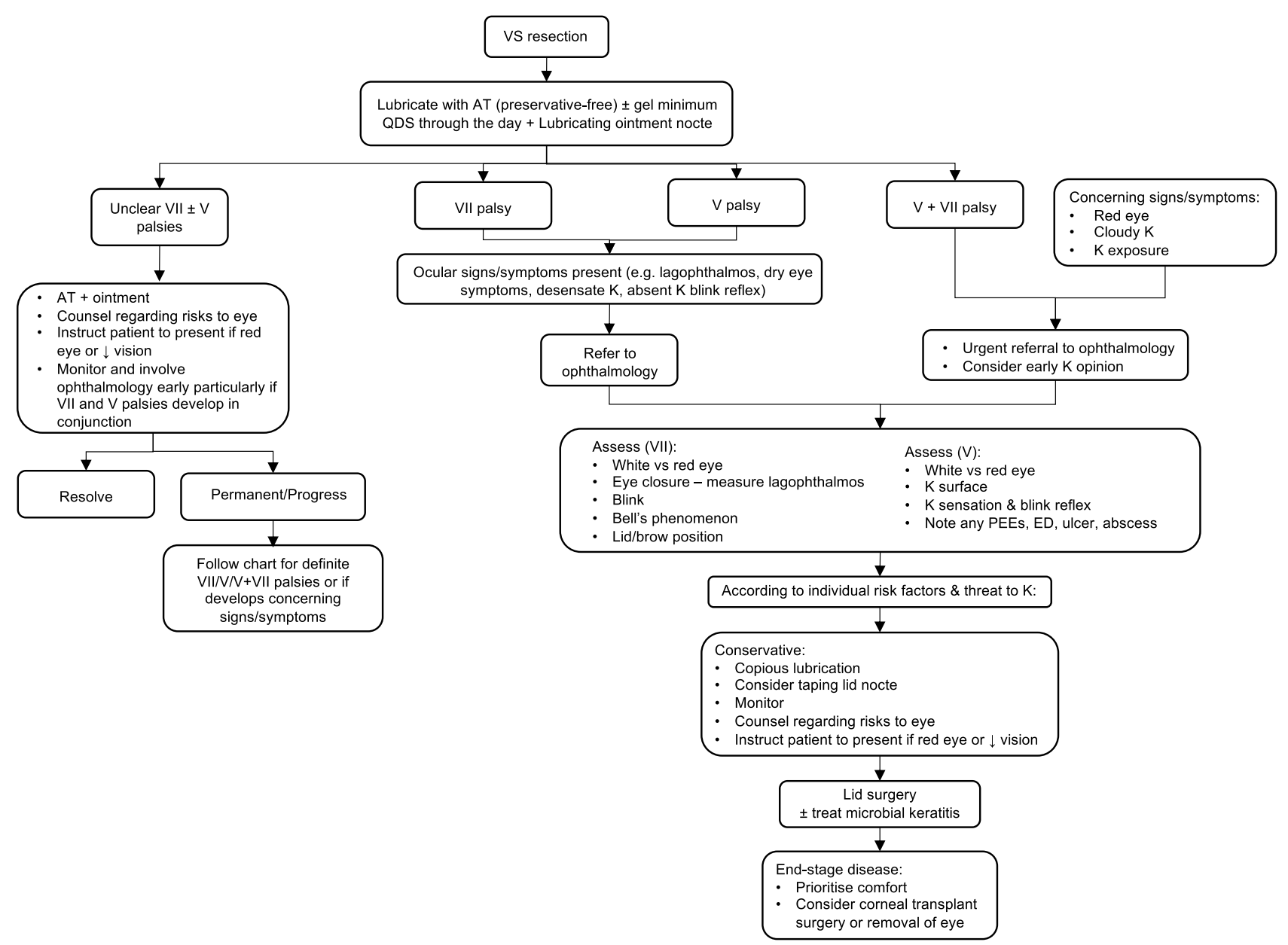

Figure 3 Suggested management algorithm for $\mathrm{V}$ and VII nerve palsies with ocular involvement following vestibular schwannoma (VS) resection. Artificial tears (AT); trigeminal nerve (V); facial nerve (VII); cornea/corneal (K); four times a day (QDS).

for VS) and who developed skew deviations post-operation; all of whom recovered within 10 weeks. ${ }^{56}$ They suggested that these skew deviations occurred as a consequence of the acute deafferentation of the vestibular nerve and hence as a result of an insult to the peripheral vestibular pathway. If this is the case, one might expect that there are greatly more skew deviations amongst patients undergoing VS resection than currently reported, although the effect does seem to be transient. Indeed, as it can sometimes be a clinical challenge to differentiate between a skew deviation and an IV nerve palsy, ${ }^{57}$ there could be cross-reporting of these two different clinical entities and the neuro-ophthalmologist has an important role to play in carefully examining the patient with vertical diplopia post VS resection.

\section{Nystagmus}

Nystagmus can occur in patients with VS as a result of damage to the peripheral vestibular pathway (direct damage to the VIII nerve), or as a result of compression of the central vestibular pathway (brainstem compression from a large tumor). Both types of nystagmus are associated with symptoms of vertigo and imbalance (and not typically oscillopsia). For this reason, these patients do not often initially present to ophthalmology departments. A combination of central and peripheral vestibular nystagmus from a lesion in the cerebello-pontine angle can classically result in "Brun's nystagmus". In Brun's nystagmus there is a coarse, ipsilaterally beating nystagmus when looking towards the side of the lesion (central nystagmus as a result of compression of the pons) and fine, contralaterally beating nystagmus when looking away from the side of the lesion (peripheral nystagmus as a result of damage to the VIII nerve fibers) ${ }^{58,59}$ However, the nystagmus seen with VSs is often not obviously localizing, either to the side of the lesion or following a classical bidirectional Brun's type. ${ }^{31,45}$ As well as nystagmus, impaired vestibular dysfunction from a growing VS can result in disrupted optokinetic nystagmus, abnormal smooth pursuit movements and abnormal saccades. ${ }^{60}$ 
Nystagmus (and particularly Brun's nystagmus) becomes more common with larger tumors, although the reported rates of nystagmus prior to VS resection vary widely from $0 \%$ to $36 \%{ }^{31,45,59-61}$ In a prospective study of 47 patients having VS resection, Čada et al examined all patients pre- and postresection with electronystagmography. ${ }^{60}$ They found that whilst no patients had spontaneous nystagmus in the immediate pre-operative period, $55 \%$ had spontaneous nystagmus in the early post-operative period. In another study of 32 patients who had undergone VS resection between 1 month and 6 years previously, $42 \%$ patients had spontaneous nystagmus in the dark and $100 \%$ patients had nystagmus following hyperventilation. ${ }^{62}$ Hyperventilation appeared to unmask the underlying VIII nerve deficit, presumably by decreasing cerebral blood flow and adversely affecting central compensatory mechanisms. In all cases, the nystagmus post VS resection was contralaterally beating. In contrast, two cases of patients with VS treated with stereotactic radiosurgery have been reported to show hyperventilation induced, ipsilaterally beating nystagmus. ${ }^{63}$ The mechanism is felt to be that the radiosurgery causes demyelination of the VIII nerve without completely disrupting axonal transmission; hyperventilation then causes a transient metabolic alkalosis, which lowers extracellular calcium levels and increases axonal activity along these partially demyelinated nerve fibers causing an irritative type of nystagmus. A similar pattern of hyperventilation-induced ipsilaterally beating nystagmus can be seen in un-operated VSs which are not causing complete destruction of the VIII nerve. ${ }^{62}$

After an acute vestibular insult (as in VS resection) central compensation develops, and symptoms and signs of vestibular dysfunction improve. Interestingly, patients with less damage to the VIII nerve prior to VS resection (who have smaller tumors and/or preserved hearing) are more likely to experience transient vestibular dysfunction following surgery. ${ }^{60,64}$ This is probably because an acute insult occurs to the VIII nerve at the time of surgery as opposed to a more insidious insult alongside central compensation, which occurs with a slow growing tumor. Vestibular function, which worsens in the early post-operative period, can be expected to return to pre-resection levels 3 months post surgery, ${ }^{60,64}$ but nevertheless, reported balance problems may remain for up to $90 \%$ of patients who have undergone VS resection. ${ }^{9}$

Nystagmus following VS surgery may also indicate an early post-operative vascular complication, and this is particularly the case if it is not contralaterally beating as should be expected. Kania et al reported two such cases in their series of 432 patients who developed nystagmus beating towards the side of the resected lesion in the early post-operative period. ${ }^{65}$ One patient experienced nausea and vomiting at day 3 post VS resection. He had ipsilaterally beating nystagmus and other cerebellar signs, the cause being an arterial infarct of the anterior inferior cerebellar artery. The second case experienced severe headache at day 2 post VS-resection with nystagmus but no other cerebellar signs. Imaging revealed a cerebello-pontine angle hematoma. In both these cases, the nystagmus resolved within 4 weeks.

\section{Papilledema}

Papilledema refers to optic disc swelling due to raised intracranial pressure. Chronically swollen optic discs can become pale and atrophic. In the setting of a VS, papilledema may occur due to the mass effect of a large tumor causing compression of the brainstem with resultant obstruction of cerebrospinal fluid (CSF) flow through the fourth ventricle (obstructive hydrocephalus). It is also well recognized that raised CSF pressure can occur without demonstrable obstructive hydrocephalus on imaging. This is as a consequence of raised CSF protein causing interruption to CSF resorption. ${ }^{5,66-69}$ Furthermore, papilledema may occur post VS resection as a result of postoperative cerebral venous sinus thrombosis. ${ }^{5,70}$

Raised intracranial pressure may be asymptomatic, or there may be other neurological symptoms (including pulsatile tinnitus and non-specific paresthesias or weakness). There may also be visual symptoms which include blurred vision (as a result of optic nerve dysfunction or from induced hypermetropia); transient visual obscurations (blacking out of vision in one or both eyes for a matter of seconds and often associated with stooping or straining); and photopsias (flashes or zigzags of light). ${ }^{71}$ The visual fields may be affected in a variety of ways ranging from an enlarged blind spot (not usually a hindrance to the patient) through to extensive loss of peripheral and/or central fields and blindness. ${ }^{72,73}$

Papilledema at the time of presentation with VSs is relatively uncommon, but with large tumors $(>4 \mathrm{~cm})$ it may be present in up to $20 \%$ of cases, ${ }^{22,47}$ and papilledema with or without visual dysfunction can be the presenting feature of a VS. ${ }^{5,74}$ Where there is evidence of visual dysfunction (for example, transient visual obscurations, visual field changes and reduced visual acuity), then care needs to be taken to preserve vision, and management may involve urgent CSF drainage via an external ventricular 
drain or optic nerve sheath fenestration prior to resection of the tumor. ${ }^{5}$

If papilledema occurs following VS resection, with or without other symptoms, then a cerebral venous sinus thrombosis needs to be excluded. Cerebral venous sinus thrombosis is a recognized complication of skull-based surgery with reported rates following VS surgery varying between $5 \%$ and $30 \% .^{70,75,76}$ Figure 4 shows a post-VSresection venogram for a patient who developed transverse venous sinus thrombosis with associated papilledema and central visual disturbance post-operatively. First-line management of cerebral venous sinus thrombosis involves careful anticoagulation. ${ }^{76,77}$ We have also previously reported on the potential role of optic nerve sheath fenestration in post VS-resection cerebral venous sinus thrombosis with threatened vision. ${ }^{5}$

\section{Miscellaneous}

A handful of other rarer neuro-ophthalmic complications have been reported following VS resection. There has been a single case report of orbital compartment syndrome (with exophthalmos, orbital pain, decreased visual acuity, and dilation of the superior ophthalmic vein on imaging) following VS resection by a middle fossa approach; the symptoms and signs resolved without further treatment. ${ }^{78}$ One series reported two cases $(1.1 \%)$ of peri-orbital cellulitis following

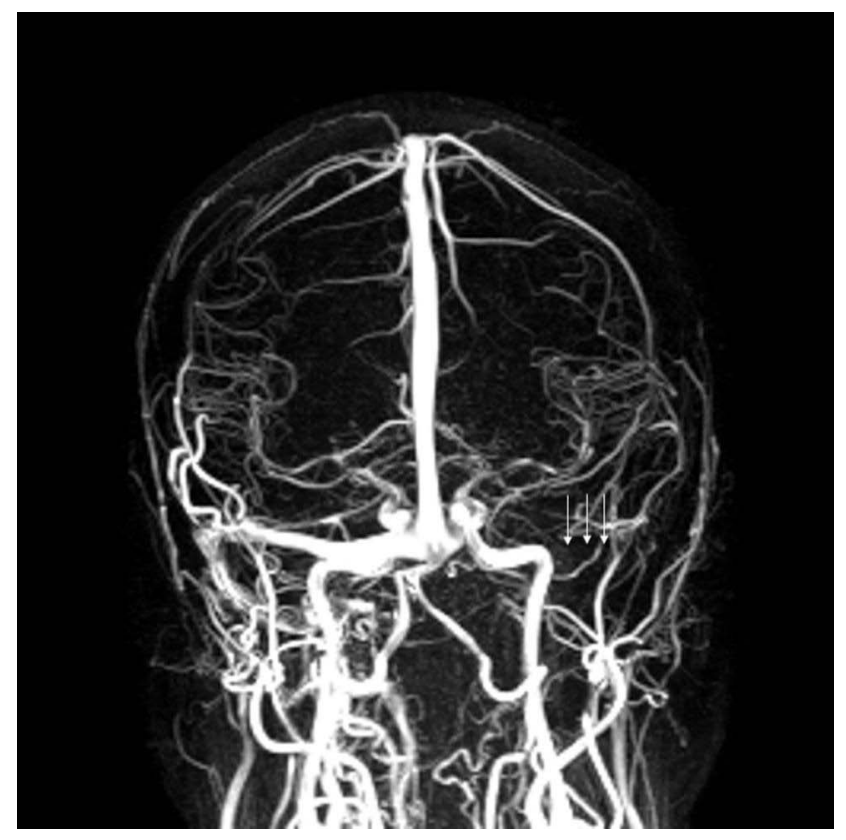

Figure 4 Magnetic resonance venogram following resection of a left vestibular schwannoma showing absence of filling of the left transverse venous sinus (arrows) due to a transverse venous sinus thrombosis.
VS resection. ${ }^{16}$ Finally, Roland et al reported one case of a persistent Horner's syndrome following resection of a VS. ${ }^{54}$ This was, however, associated with a severe sialadenitis (salivary gland inflammation) and a large neck phlegmon, which also caused a temporary palsy of the lower cranial nerves and the brachial plexus.

\section{Conclusions}

Reviewing the published literature reveals that there are very high rates of patient reported eye and visual symptoms following VS resection, with over $90 \%$ patients reporting eye symptoms and $50 \%$ impaired vision following VS surgery. ${ }^{8-10}$ The underlying reasons for these troublesome symptoms are likely a combination of the neuro-ophthalmic consequences from VS resection. Corneal dryness, opacification and ulceration as a consequence of VII and V nerve dysfunction are the most common reasons for reported poor vision and eye symptoms. . $^{31,34,35}$ Indeed, best corrected visual acuity correlates with corneal sensation following VS resection, with poorer corneal sensation associated with poorer visual acuity. ${ }^{34}$ The consequences of corneal disease can in rare cases lead to devastating visual loss, globe perforation and the need for removal of the eye. ${ }^{34}$

Less common, but important explanations for reported visual disturbance, are strabismus, nystagmus and papilledema. The most common reason for strabismus is a VI nerve palsy. This may be a false localizing sign in patients with large tumors and raised intracranial pressure, or as a result of intra-operative trauma to the VI nerve. A VI nerve palsy will exacerbate the effects of corneal exposure, which may already be present from a VII and/or V nerve palsy by placing the eye in an adducted position where exposure is maximal. VI nerve palsies and other neurogenic causes of strabismus following VS resection often improve spontaneously. The insult to the vestibular system from VS surgery can cause vestibular dysfunction with associated imbalance. The expected pattern of nystagmus post VS resection is contralaterally beating. This will improve spontaneously as central compensation occurs, but some nystagmus and balance dysfunction may persist. Both nystagmus (particularly if ipsilaterally beating) and papilledema following VS resection can be signs of serious post-operative vascular complications and should prompt urgent investigation. Papilledema following VS surgery should raise a high suspicion of cerebral venous sinus thrombosis.

The rates of neuro-ophthalmic complications following VS treatment (particularly those from VII nerve damage) can be improved with intra-operative VII nerve monitoring, 
leaving a tumor remnant around the VII nerve and then meticulous early post-operative eye care. ${ }^{16,25}$ Using Gamma knife radiosurgery as an alternative treatment to VS resection where appropriate may also reduce the neuro-ophthalmic consequences of VS treatment when compared to surgery. ${ }^{30,79}$

The most important factor contributing to complications following resection is tumor size, with larger tumors having larger rates of neuro-ophthalmic complications. This needs to be considered for patients under a "waitand-scan" approach as there may be an optimal tumor size at which intervention should be considered. ${ }^{80}$

In summary, common neuro-ophthalmic complications from VS resection include V and VII nerve damage, while less common complications include double vision, nystagmus and papilledema. All of these complications result in high rates of reported eye and vision troubles in patients following VS resection. The rates of complications rise with increasing tumor size.

\section{Disclosure}

The authors report no conflicts of interest in this work.

\section{References}

1. Carlson ML, Link MJ, Ingelfinger JR. Vestibular schwannomas. $N$ Engl $J$ Med. 2021;384(14):1335-1348. doi:10.1056/NEJMra202 0394

2. Marinelli JP, Lohse CM, Carlson ML. Incidence of vestibular schwannoma over the past half-century: a population-based study of Olmsted County, Minnesota. Otolaryngol Head Neck Surg. 2018;159(4):71 7-723. doi:10.1177/0194599818770629

3. Reznitsky M, Petersen M, West N, Stangerup SE, Caye-Thomasen P. Epidemiology of vestibular schwannomas - prospective 40-year data from an unselected national cohort. Clin Epidemiol. 2019;11:981-986. doi: $10.2147 /$ CLEP.S2 18670

4. Wright A, Bradford R. Management of acoustic neuroma. BMJ. 1995;311(7013):1141-1144. doi:10.1136/bmj.311.7013.1141

5. Jefferis JM, Raoof N, Carroll T, Salvi SM. Optic nerve sheath fenestration in patients with visual failure associated with vestibular schwannoma. Br J Neurosurg. 2019;33(4):402-408. doi:10.1080/ 02688697.2018 .1538482

6. Carlson ML, Glasgow AE, Grossardt BR, Habermann EB, Link MJ. Does where you live influence how your vestibular schwannoma is managed? Examining geographical differences in vestibular schwannoma treatment across the United States. J Neurooncol. 2016;129 (2):269-279. doi:10.1007/s11060-016-2170-5

7. Ryzenman JM, Pensak ML, Tew JM. Patient perception of comorbid conditions after acoustic neuroma management: survey results from the acoustic neuroma association. Laryngoscope. 2004;114 (5):814-820. doi:10.1097/00005537-200405000-00005

8. Tos T, Caye-Thomasen P, Stangerup SE, Thomsen J, Tos M. Need for facial reanimation after operations for vestibular schwannoma: patients perspective. Scand J Plast Reconstr Surg Hand Surg. 2003;37 (2):75-80. doi:10.1080/02844310310005595

9. Al-Shudifat AR, Kahlon B, Höglund P, Lindberg S, Magnusson M, Siesjo P. A patient-assessed morbidity to evaluate outcome in surgically treated vestibular schwannomas. World Neurosurg. 2016;94:54450.e2. doi:10.1016/j.wneu.2016.07.043
10. Tamura M, Murata N, Hayashi M, Régis J. Injury of the lacrimal component of the nervus intermedius function after radiosurgery versus microsurgery. Neurochirurgie. 2004;50(2-3 Pt2):338-344.

11. Sampath P, Holliday MJ, Brem H, Niparko JK, Long DM. Facial nerve injury in acoustic neuroma (vestibular schwannoma) surgery: etiology and prevention. $J$ Neurosurg. 1997;87(1):60-66. doi:10.3171/jns.1997.87.1.0060

12. Wexler DB, Fetter TW, Gantz BJ. Vestibular schwannoma presenting with sudden facial paralysis. Arch Otolaryngol Head Neck Surg. 1990;116(4):483-485. doi:10.1001/ archotol.1990.01870040105024

13. Mastronardi L, Cacciotti G, Roperto R. Intracanalicular vestibular schwannomas presenting with facial nerve paralysis. Acta Neurochir. 2018;160(4):689-693. doi:10.1007/s00701-018-3498-8

14. Lee TK, Lund WS, Adams CB. Factors influencing the preservation of the facial nerve during acoustic surgery. Br J Neurosurg. 1990;4 (1):5-8. doi:10.3109/02688699009000675

15. Jørgensen BG, Pedersen CB. Acoustic neuroma. Follow-up of 78 patients. Clin Otolaryngol Allied Sci. 1994;19(6):478-484. doi:10.1111/j.1365-2273.1994.tb01273.x

16. Gange WS, Kirchner ID, Thompson JA, et al. Ophthalmic complications following acoustic neuroma resection. Oper Neurosurg. 2018;14(1):58-65. doi:10.1093/ons/opx071

17. Hardy DG, Macfarlane R, Baguley DM, Moffat DA. Facial nerve recovery following acoustic neuroma surgery. $\mathrm{Br} J$ Neurosurg. 1989;3(6):675-680. doi:10.3109/02688698908992691

18. Mamikoglu B, Wiet RJ, Esquivel CR. Translabyrinthine approach for the management of large and giant vestibular schwannomas. Otol Neurotol. 2002;23(2):224-227. doi:10.1097/00129492-200203000-00020

19. Dandinarasaiah M, Prasad SC, Piccirillo E, et al. Facial nerve outcomes following total excision of vestibular schwannoma by the enlarged translabyrinthine approach. Otol Neurotol. 2019;40 (2):226-235. doi:10.1097/MAO.0000000000002068

20. Graffeo CS, Perry A, Raghunathan A, et al. Macrophage density predicts facial nerve outcome and tumor growth after subtotal resection of vestibular schwannoma. J Neurol Surg B Skull Base. 2018;79 (5):482-488. doi:10.1055/s-0038-1627474

21. Sobieski C, Killeen DE, Barnett SL, et al. Facial nerve outcomes after vestibular schwannoma microsurgical resection in neurofibromatosis type 2. Otolaryngol Head Neck Surg. 2021;164(4):850-858. doi:10.1177/0194599820954144

22. Giordano AI, Domènech I, Torres A, et al. Results in the surgical treatment of giant acoustic neuromas. Acta Otorrinolaringol Esp. 2012;63(3):194-199. doi:10.1016/j.otorri.2011.11.003

23. Grinblat G, Dandinarasaiah M, Braverman I, Taibah A, Lisma D, Sanna M. Large and giant vestibular schwannomas: overall outcomes and the factors influencing facial nerve function. Neurosurg Rev. 2020;44(4):2119-2131. doi:10.1007/s10143-020-01380-6

24. Sylvester MJ, Shastri DN, Patel VM, et al. Outcomes of vestibular schwannoma surgery among the elderly. Otolaryngol Head Neck Surg. 2017;156(1):166-172. doi:10.1177/0194599816677522

25. Monfared A, Corrales CE, Theodosopoulos PV, et al. Facial nerve outcome and tumor control rate as a function of degree of resection in treatment of large acoustic neuromas: preliminary report of the Acoustic Neuroma Subtotal Resection Study (ANSRS). Neurosurgery. 2016;79(2):194-203. doi:10.1227/NEU.0000000000 001162

26. Amano M, Kohno M, Nagata O, Taniguchi M, Sora S, Sato H. Intraoperative continuous monitoring of evoked facial nerve electromyograms in acoustic neuroma surgery. Acta Neurochir. 2011;153(5):1059-67; discussion 1067. doi:10.1007/s00701-0100937-6

27. Tokimura H, Sugata S, Yamahata H, Yunoue S, Hanaya R, Arita K. Intraoperative continuous monitoring of facial motor evoked potentials in acoustic neuroma surgery. Neurosurg Rev. 2014;37(4): 669-676. doi:10.1007/s10143-014-0561-7 
28. Gurgel RK, Dogru S, Amdur RL, Monfared A. Facial nerve outcomes after surgery for large vestibular schwannomas: do surgical approach and extent of resection matter? Neurosurg Focus. 2012;33 (3):E16. doi:10.3171/2012.7.FOCUS12199

29. Rowe JG, Radatz MW, Walton L, Soanes T, Rodgers J, Kemeny AA. Clinical experience with gamma knife stereotactic radiosurgery in the management of vestibular schwannomas secondary to type 2 neurofibromatosis. J Neurol Neurosurg Psychiatry. 2003;74(9):12 88-1293. doi:10.1136/jnnp.74.9.1288

30. Mezey G, Cahill J, Rowe JG, et al. A retrospective analysis of the role of single-session gamma knife stereotactic radiosurgery in sporadic vestibular schwannomas with tumor volumes greater than 10 cm3: Is it worth stretching the boundaries? Stereotact Funct Neurosurg. 2020;98(2):85-94. doi:10.1159/000504857

31. Rogers NK, Brand CS. Acoustic neuroma and the eye. $\mathrm{Br}$ J Neurosurg. 1997;11(4):292-297. doi:10.1080/02688699746069

32. Welder J, Allen R, Shriver E. Facial nerve palsy: ocular complications and management; July 14, 2015. Available from: http:// EyeRounds.org/cases/215-facial-nerve.htm. Accessed July 20, 2021.

33. Irving RM, Viani L, Hardy DG, Baguley DM, Moffat DA. Nervus intermedius function after vestibular schwannoma removal: clinical features and pathophysiological mechanisms. Laryngoscope. 1995;105(8 Pt 1):809-813. doi:10.1288/00005537-199508000-00007

34. Mulhern MG, Aduriz-Lorenzo PM, Rawluk D, Viani L, Eustace P, Logan P. Ocular complications of acoustic neuroma surgery. $\mathrm{Br}$ J Ophthalmol. 1999;83(12):1389-1392. doi:10.1136/bjo.83.12.1389

35. Sadiq SA, Downes RN. A clinical algorithm for the management of facial nerve palsy from an oculoplastic perspective. Eye. 1998;12(Pt 2):219-223. doi:10.1038/eye.1998.52

36. House JW, Brackmann DE. Facial nerve grading system. Otolaryngol Head Neck Surg. 1985;93(2):146-147. doi:10.1177/01945998850930 0202

37. Meadows A, Hall N, Shah-Desai S, Low JL, Manners R. The House-Brackmann system and assessment of corneal risk in facial nerve palsy. Eye. 2000;14(Pt 3A):353-357. doi:10.1038/eye.2000.87

38. Choi D, Raisman G. After facial nerve damage, regenerating axons become aberrant throughout the length of the nerve and not only at the site of the lesion: an experimental study. Br J Neurosurg. 2004;18 (1):45-48. doi:10.1080/02688690410001660454

39. Portelinha J, Passarinho MP, Costa JM. Neuro-ophthalmological approach to facial nerve palsy. Saudi J Ophthalmol. 2015;29 (1):39-47. doi:10.1016/j.sjopt.2014.09.009

40. Chen C, Malhotra R, Muecke J, Davis G, Selva D. Aberrant facial nerve regeneration (AFR): an under-recognized cause of ptosis. Eye. 2004;18(2):159-162. doi:10.1038/sj.eye.6700599

41. Khosla S, Elliot M, Donnelly N. Bilateral otoneurological pathology: To operate or not? Cochlear Implants Int. 2017;18(2):121-124. doi:10.1080/14670100.2017.1289605

42. Rajak S, Rajak J, Selva D. Performing a tarsorrhaphy. Community Eye Health. 2015;28(89):10-11.

43. Chi JJ. Management of the eye in facial paralysis. Facial Plast Surg Clin North Am. 2016;24(1):21-28. doi:10.1016/j.fsc.2015.09.003

44. Nazzi V, Marras C, Broggi G. Upper eyelid gold weight implants in patients with facial nerve palsy surgical technique. J Neurosurg Sci. 2006;50(4):107-110.

45. van Meter WS, Younge BR, Harner SG. Ophthalmic manifestations of acoustic neurinoma. Ophthalmology. 1983;90(8):917-922. doi:10. 1016/s0161-6420(83)80017-7

46. Karkas A, Lamblin E, Meyer M, Gay E, Ternier J, Schmerber S. Trigeminal nerve deficit in large and compressive acoustic neuromas and its correlation with MRI findings. Otolaryngol Head Neck Surg. 2014;151(4):675-680. doi:10.1177/0194599814545440

47. Jung S, Kang SS, Kim TS, et al. Current surgical results of retrosigmoid approach in extralarge vestibular schwannomas. Surg Neurol. 2000;53(4):370-377. doi:10.1016/s0090-3019(00)00196-8
48. Goren SB. Cataract associated with long-term facial paralysis. Am $J$ Ophthalmol. 1975;80(2):300-302. doi:10.1016/0002-9394(75) 90150-6

49. Lambiase A, Sacchetti M, Mastropasqua A, Bonini S. Corneal changes in neurosurgically induced neurotrophic keratitis. JAMA Ophthalmol. 2013;131(12):1547-1553. doi:10.1001/jamaophthalmol. 2013.5064

50. Sacchetti M, Lambiase A. Diagnosis and management of neurotrophic keratitis. Clin Ophthalmol. 2014;8:571-579. doi:10.2147/ OPTH.S45921

51. Rauz S, Kolli S. Cornea. In: Denniston A, Murray P, editors. Oxford Handbook of Ophthalmology. Oxford university press; 2014:215-286.

52. Coca Pelaz A, Fernández Lisa C, Ramón Gómez J, Pablo Rodrigo J, Luis Llorente J, Suárez C. Complete facial palsy following surgery for acoustic nerve neurinoma: evolution and associated ophthalmological complications. Acta Otorrinolaringol. 2008;59(5):223-227. doi:10.1016/s2173-5735(08)70227-8

53. McClelland S 3rd, Guo H, Okuyemi KS. Morbidity and mortality following acoustic neuroma excision in the United States: analysis of racial disparities during a decade in the radiosurgery era. Neuro Oncol. 2011;13(11):1252-1259. doi:10.1093/neuonc/nor118

54. Roland JT Jr., Fishman AJ, Golfinos JG, Cohen N, Alexiades G, Jackman AH. Cranial nerve preservation in surgery for large acoustic neuromas. Skull Base. 2004;14(2):85-90; discussion 90-1. doi:10. 1055/s-2004-828699

55. Tamhankar M. 15-eye movement disorders: third, fourth, and sixth nerve palsies and other causes of diplopia and ocular misalignment. In: Liu G, Volpe N, Galetta S, editors. Liu, Volpe, and Galetta's Neuro-Ophthalmology. 3rd ed. Elsevier; 2019:489-547.

56. Cosetti MK, Tawfik K, Fouladvand M, Roland JT, Lalwani AK. Diplopia due to skew deviation following neurotologic procedures. Otol Neurotol. 2012;33(5):840-842. doi:10.1097/MAO.0b013e3182595269

57. Lemos J, Subei A, Sousa M, et al. Differentiating acute and subacute vertical strabismus using different head positions during the upright-supine test. JAMA Ophthalmol. 2018;136(4):322-328. doi:10.1001/jamaophthalmol.2017.6796

58. Croxson GR, Moffat DA, Baguley D. Bruns bidirectional nystagmus in cerebellopontine angle tumours. Clin Otolaryngol Allied Sci. 1988;13(2):153-157. doi:10.1111/j.1365-2273.1988.tb00756.x

59. Lloyd SK, Baguley DM, Butler K, Donnelly N, Moffat DA. Bruns' nystagmus in patients with vestibular schwannoma. Otol Neurotol. 2009;30(5):625-628. doi:10.1097/MAO.0b013e3181a32bec

60. Čada Z, Balatkova Z, Cakrt O, et al. Predictors of central vestibular compensation after surgery for vestibular schwannomas. Acta Otorhinolaryngol Ital. 2019;39(1):46-52. doi:10.14639/0392-100X1963

61. Day AS, Wang CT, Chen CN, Young YH. Correlating the cochleovestibular deficits with tumor size of acoustic neuroma. Acta Otolaryngol. 2008;128(7):756-760. doi:10.1080/00016480701749240

62. Bance ML, O'Driscoll M, Patel N, Ramsden RT. Vestibular disease unmasked by hyperventilation. Laryngoscope. 1998;108(4 Pt 1):610-614. doi:10.1097/00005537-199804000-00027

63. Bradley JP, Hullar TE, Neely JG, Goebel JA. Hyperventilationinduced nystagmus and vertigo after stereotactic radiotherapy for vestibular schwannoma. Otol Neurotol. 2011;32(8):1336-1338. doi:10.1097/MAO.0b013e31822e8666

64. Uehara N, Tanimoto H, Nishikawa T, et al. Vestibular dysfunction and compensation after removal of acoustic neuroma. $J$ Vestib Res. 2011;21(5):289-295. doi:10.3233/VES-2011-0429

65. Kania RE, Herman P, Lot G, Huy PT. Ipsilateral beating nystagmus after acoustic schwannoma resection. Auris Nasus Larynx. 2004;31 (1):69-72. doi:10.1016/j.anl.2003.09.007

66. van Crevel H. Papilloedema, CSF pressure, and CSF flow in cerebral tumours. J Neurol Neurosurg Psychiatry. 1979;42(6):493-500. doi:10.1136/jnnp.42.6.493 
67. Gardner WJ, Spitler DK, Whitten C. Increased intracranial pressure caused by increased protein content in the cerebrospinal fluid; an explanation of papilledema in certain cases of small intracranial and intraspinal tumors, and in the Guillain-Barre syndrome. $N$ Engl J Med. 1954;250(22):932-936. doi:10.1056/NEJM195406032502202

68. Thomas DA, Trobe JD, Cornblath WT. Visual loss secondary to increased intracranial pressure in neurofibromatosis type 2. Arch Ophthalmol. 1999;117(12):1650-1653.

69. Grainger J, Dias PS. Case report: optic disc edema without hydrocephalus in acoustic neuroma. Skull Base. 2005;15(1):83-86. doi:10.1055/s-2005-868165

70. Abou-Al-Shaar H, Gozal YM, Alzhrani G, Karsy M, Shelton C, Couldwell WT. Cerebral venous sinus thrombosis after vestibular schwannoma surgery: a call for evidence-based management guidelines. Neurosurg Focus. 2018;45(1):E4. doi:10.3171/2018.4. FOCUS18112

71. Pane A, Burdon M, Miller N. Papilloedema. In: Parkinson M, Leng H, eds.The Neuro-Ophthalmology Survival Guide. Mosby, Elsevier; 2007:130-138.

72. Kedar S, Ghate D, Corbett JJ. Visual fields in neuro-ophthalmology. Indian J Ophthalmol. 2011;59(2):103-109. doi:10.4103/0301-4738. 77013

73. Schirmer CM, Hedges TR 3rd. Mechanisms of visual loss in papilledema. Neurosurg Focus. 2007;23(5):E5. doi:10.3171/FOC07/11/E5

74. Ronan GP, Gailani G, Costello C, Sweeney B. "Should have gone to ...": bilateral papilloedema with normal CSF pressure due to vestibular schwannoma. BMJ Case Rep. 2020;13(12):Dec. doi:10. 1136/bcr-2020-239406
75. Benjamin CG, Sen RD, Golfinos JG, et al. Postoperative cerebral venous sinus thrombosis in the setting of surgery adjacent to the major dural venous sinuses. J Neurosurg. 2018:131(4):1-7. doi:10. 3171/2018.4.JNS18308.

76. Moore J, Thomas P, Cousins V, Rosenfeld JV. Diagnosis and management of dural sinus thrombosis following resection of cerebellopontine angle tumors. J Neurol Surg B Skull Base. 2014;75(6):402-408. doi:10.1055/s-0034-1376421

77. Einhaupl KM, Villringer A, Meister W, et al. Heparin treatment in sinus venous thrombosis. Lancet. 1991;338(8767):597-600. doi:10. 1016/0140-6736(91)90607-q

78. Hiyama H, Kasuya H, Dan S, Hori T. Orbital syndrome after a surgery of vestibular schwannoma via middle fossa approach. Acta Neurochir. 2003;145(1):83-85. doi:10.1007/s00701-002-10 37-z

79. Flickinger JC, Kondziolka D, Niranjan A, Lunsford LD. Results of acoustic neuroma radiosurgery: an analysis of 5 years' experience using current methods. J Neurosurg. 2001;94(1):1-6. doi:10.3171/ jns.2001.94.1.0001

80. Gjuric M, Rudic M. What is the best tumor size to achieve optimal functional results in vestibular schwannoma surgery? Skull Base. 2008;18(5):317-325. doi:10.1055/s-0028-1086056
Eye and Brain

\section{Publish your work in this journal}

Eye and Brain is an international, peer-reviewed, open access journal focusing on clinical and experimental research in the field of neuroophthalmology. All aspects of patient care are addressed within the journal as well as basic research. Papers covering original research, basic science, clinical and epidemiological studies, reviews and

Submit your manuscript here: https://www.dovepress.com/eye-and-brain-journal
Dovepress

evaluations, guidelines, expert opinion and commentary, case reports and extended reports are welcome. The manuscript management system is completely online and includes a very quick and fair peerreview system, which is all easy to use. Visit http://www.dovepress. com/testimonials.php to read real quotes from published authors. 